\title{
Covalent Attachment of Polyoxometalates to Passivated Si(111) Substrates: A Stable and Electronic Defect-Free Si|POM Platform
}

\author{
Joseph M. Gurrentz and Michael J. Rose* \\ Department of Chemistry, University of Texas at Austin; Austin, TX 78712, USA \\ *corresponding author: mrose@cm.utexas.edu
}

Table of Contents

Page

Synthesis and NMR Characterization

Figure S1

Table S1

Figure S2

Figure S3

S7

Figure S4

S8

Figure S5

S9

Figure S6

S10

Figure $\mathbf{S 7}$

S11

References

S12 


\section{Synthesis and NMR Characterization}

$\mathrm{HGeCl}_{3} \cdot 2\left(\mathrm{C}_{2} \mathrm{H}_{5}\right)_{2} \mathrm{O}$ (Trichlorogermane etherate)

A two-neck round bottom flask (RBF) containing a magnetic stir bar was fitted with a reflux condenser and a rubber septum. The manifold was purged of air and refilled with an $\mathrm{N}_{2}$ atmosphere, after which diethyl ether $\left(\mathrm{Et}_{2} \mathrm{O}, 30 \mathrm{~mL}\right)$ and $\mathrm{GeCl}_{4}(9.33 \mathrm{mmol}, 1.08 \mathrm{~mL})$ were added. Tetramethyldisiloxane (TMDS, 9.33 mmol, $1.64 \mathrm{~mL}$ ) was added to the stirring solution, at which point the $\mathrm{RBF}$ was heated to $40^{\circ} \mathrm{C}$ and allowed to stir for $4.5 \mathrm{~h}$. After this duration, the reaction mixture split into two phases, indicating completion. An opaque, pale yellow-green oil settled on the bottom, and a clear layer containing excess ether was removed from the top by pipette. The remaining oil layer containing the trichlorogermane etherate product was used immediately in the next reaction.

\section{$\mathrm{Cl}_{3} \mathrm{Ge}\left(\mathrm{CH}_{2}\right)_{2} \mathrm{COOH}$}

To neat, freshly prepared trichlorogermane etherate $(9.33 \mathrm{mmol})$ in a two-neck RBF under $\mathrm{N}_{2}$ atmosphere was added acrylic acid $(11.66 \mathrm{mmol}, 0.8 \mathrm{~mL})$. The solution was allowed to stir overnight, then volatiles were removed via rotary evaporation yielding a pale yellow-green oil. The product was extracted into $\mathrm{CHCl}_{3}$, and solvent was removed under reduced pressure, yielding the product as a sticky off-white solid. Yield: $\sim 30 \% .{ }^{1} \mathrm{H}$ NMR $\left(\mathrm{CDCl}_{3}\right): \delta 2.86(\mathrm{t} 2 \mathrm{H}), 2.30(\mathrm{t} 2 \mathrm{H}) \mathrm{ppm}$.

$\left[\mathrm{N}\left(\mathrm{C}_{4} \mathrm{H}_{9}\right)_{4}\right]_{4} \mathrm{H}_{3}\left[\mathrm{P} W_{11} \mathrm{O}_{39}\right]$

$\mathrm{Na}_{2} \mathrm{HPO}_{4}(1.38 \mathrm{mmol}, 196 \mathrm{mg})$ and $\mathrm{Na}_{2} \mathrm{WO}_{4} \cdot 2 \mathrm{H}_{2} \mathrm{O}(15.15 \mathrm{mmol}, 5.0 \mathrm{~g})$ were dissolved in $10 \mathrm{~mL}$ deionized water in a beaker with a stir bar. $1 \mathrm{~mL} 12 \mathrm{M} \mathrm{HCl}$ was added dropwise over $\sim 15 \mathrm{~min}$ to the vigorously stirring solution. White flaky precipitate formed upon each acid aliquot addition, which was allowed to dissolve before further acid aliquots were added. The solution was let to stir $1 \mathrm{~h}$ before the $\mathrm{pH}$ of the solution was adjusted to $\mathrm{pH}=5.5$ using $12 \mathrm{M} \mathrm{HCl}$. Aliquots of dilute $(3 \mathrm{M}) \mathrm{HCl}$ were added to maintain this $\mathrm{pH}$ value $\pm 0.2 \mathrm{pH}$ units while the solution was stirred for an additional $30 \mathrm{~min}$. Next, a separately prepared 
solution of tetrabutylammonium bromide $\left(2.0 \mathrm{~g}\right.$ in $\left.15 \mathrm{~mL} \mathrm{H}_{2} \mathrm{O}\right)$ was added to the stirring reaction solution, and the product precipitated at once as a fluffy white solid. Precipitation was completed by adding $3 \mathrm{M} \mathrm{HCl}$ until the $\mathrm{pH}=1.1-1.2$, and this $\mathrm{pH}$ was maintained for $5 \mathrm{~min}$. The mixture was subsequently vacuum filtered, and the precipitate was washed with DI water and $\mathrm{Et}_{2} \mathrm{O}$. Remaining volatiles were removed under reduced pressure, yielding the pure product as a fluffy white powder. Yield: $94 \% .{ }^{1} \mathrm{H}$ NMR $\left(\left(\mathrm{CD}_{3}\right)_{2} \mathrm{SO}\right): \delta$ $3.17(\mathrm{~m} \mathrm{32H}), 1.57(\mathrm{~m} \mathrm{32H}), 1.31(\mathrm{~m} \mathrm{32H}), 0.84(\mathrm{t}, 48 \mathrm{H})$ ppm. ${ }^{31} \mathrm{P}-\mathrm{NMR}\left(\mathrm{CD}_{3} \mathrm{CN}\right): \delta-13.29 \mathrm{ppm}$.

$\left[\mathrm{N}\left(\mathrm{C}_{4} \mathrm{H}_{9}\right)_{4}\right]_{4}\left[\mathrm{PW} \mathrm{W}_{11} \mathrm{O}_{39}\left(\mathrm{Ge}\left(\mathrm{CH}_{2}\right)_{2} \mathrm{COOH}\right)\right]$

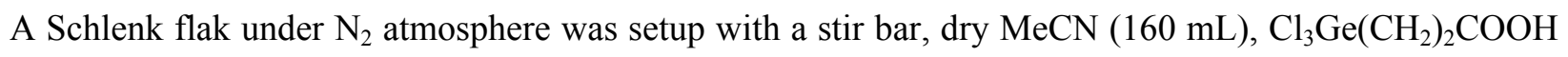
(0.992 mmol, $0.250 \mathrm{~g})$, and triethylamine (TEA, $1.505 \mathrm{mmol} 210 \mu \mathrm{L})$, in that order. This solution was stirred at room temperature overnight, after which volatiles were removed under reduced pressure. The resulting residue was dissolved in acetone $(10 \mathrm{~mL})$, and a white product was precipitated by the addition of 10:1 $\mathrm{Et}_{2} \mathrm{O} /$ ethanol $(10 \mathrm{~mL})$. The resulting precipitate was vacuum filtered then dried in air, yielding the pure product as an off-white crystalline powder. Yield: 30\%. ${ }^{1} \mathrm{H}$ NMR $\left(\mathrm{CD}_{3} \mathrm{CN}\right): \delta 3.00(\mathrm{~m} \mathrm{32H}), 1.79(\mathrm{t} 2 \mathrm{H})$, $1.50(\mathrm{~m} 32 \mathrm{H}), 1.26(\mathrm{~m} 34 \mathrm{H}), 0.84(\mathrm{t}, 48 \mathrm{H}) \mathrm{ppm} .{ }^{31} \mathrm{P}-\mathrm{NMR}\left(\mathrm{CD}_{3} \mathrm{CN}\right): \delta-14.92 \mathrm{ppm}$. 

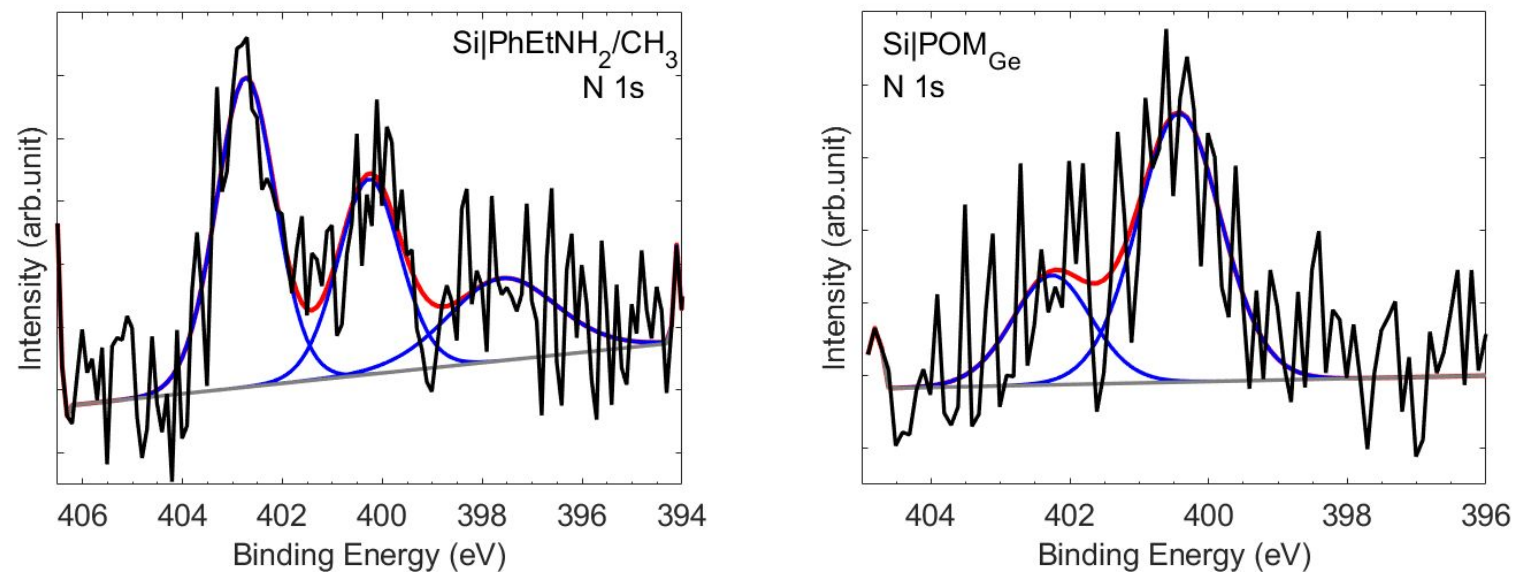

Figure S1. High resolution XP spectra in the N 1s region of $\mathbf{S i} \mid \mathbf{P h E t N H} / \mathbf{C H}_{\mathbf{3}}$ (left) and $\mathbf{S i} \mid \mathbf{P O M} \mathbf{M}_{\mathrm{Ge}}$ (right) samples. Black traces are raw data, blue traces are components used for signal integration, red traces are the sum of the blue quantification components, and gray traces represent the spectral background. 


\begin{tabular}{|c|c|c|c|c|c|c|}
\hline Peak Identity & $\begin{array}{l}\text { B.E. } \\
(\mathrm{eV})\end{array}$ & $\begin{array}{c}\text { Raw } \\
\text { Area } \\
(\mathrm{CPSeV})\end{array}$ & RSF & $\begin{array}{l}\text { Peak Area } \\
\text { / RSF } \\
(\mathrm{CPSeV})\end{array}$ & $\begin{array}{c}\text { Theoretical } \\
\text { Ideal Methyl } \\
\text { Monolayer C } \\
\text { 1s Peak Area } \\
(\mathrm{CPSeV})\end{array}$ & $\begin{array}{c}\text { Atomic } \\
\text { Surface } \\
\text { Coverage } \\
(\%)\end{array}$ \\
\hline Si $2 p_{3 / 2}$ & 99.20 & 3776.1 & 0.328 & 11512.4 & & - \\
\hline Si $2 p_{1 / 2}$ & 99.79 & 2808.1 & 0.328 & 8561.3 & 8170.9 & - \\
\hline Si $2 p\left(\mathrm{SiO}_{\mathrm{x}}\right)$ & 102.39 & 866.4 & 0.328 & 2641.4 & & 32.3 \\
\hline $\mathrm{Ge} 3 d\left(\mathrm{GeO}_{\mathrm{x}}\right)$ & 32.71 & 13.6 & 0.536 & 25.4 & - & 0.31 \\
\hline $\mathrm{W} 4 f_{7 / 2}\left(\mathrm{WO}_{x}\right)$ & 35.95 & 39.7 & 3.523 & 11.3 & - & 0.14 \\
\hline $\mathrm{W} 4 f_{5 / 2}\left(\mathrm{WO}_{x}\right)$ & 38.13 & 37.7 & 3.523 & 10.7 & & 0.13 \\
\hline $\mathrm{N} 1 s\left(\mathrm{NR}_{3}\right)$ & 400.22 & 76.2 & 0.477 & 160.0 & - & 1.95 \\
\hline $\mathrm{N} 1 s\left(\mathrm{NR}_{4}^{+}\right)$ & 403.20 & 11.9 & 0.477 & 25.0 & & 0.31 \\
\hline
\end{tabular}

Table S1. Representative raw XPS data for one sample of $\mathbf{S i} \mid \mathbf{P O M} \mathbf{M}_{\mathbf{G e}}$ demonstrating the simplified overlayer procedure used to estimate fractional monolayer coverages of atomic components. Theoretical $\mathrm{C} 1 \mathrm{~s}$ peak areas for "perfect" $100 \%-\mathrm{CH}_{3}$ passivated samples are calculated from a known empirical ratio of $\sim 1: 10$ methyl C $1 s$ to $\mathrm{Si} 2 p$, scaled to the RSF values for C $1 s$ photoelectrons from hydrocarbon overlayers (0.278) and $\mathrm{Si} 2 \mathrm{p}$ photoelectrons $(0.328) .{ }^{1}$ Molecular surface coverage values are calculated by dividing atomic surface coverages by the number of atoms of that type per molecule (e.g. there are $11 \mathrm{~W}$ atoms per POM, so the total atomic $\mathrm{W} 4 f$ coverage is divided by 11$)$. 
$(\mathrm{TBA})_{4} \mathrm{H}_{3}\left[\mathrm{PW}_{11} \mathrm{O}_{39}\right]$

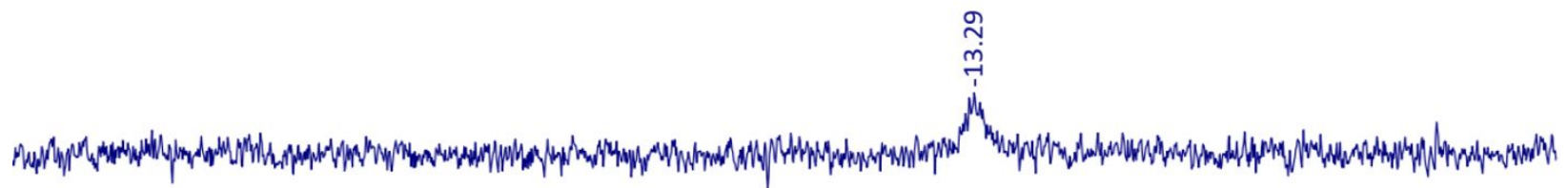
$(\mathrm{TBA})_{4}\left[\mathrm{PW}_{11} \mathrm{O}_{39}\left(\mathrm{Ge}\left(\mathrm{CH}_{2}\right)_{2} \mathrm{COOH}\right)\right]$

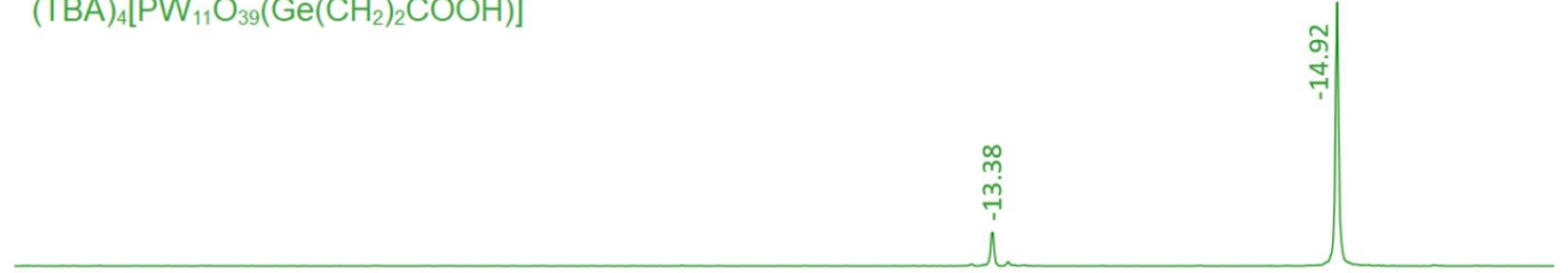

\section{$(\mathrm{TBA})_{4}\left[\mathrm{PW}_{11} \mathrm{O}_{39}\left(\mathrm{Ge}\left(\mathrm{CH}_{2}\right)_{2} \mathrm{CO}-\mathrm{R}\right]\right.$}
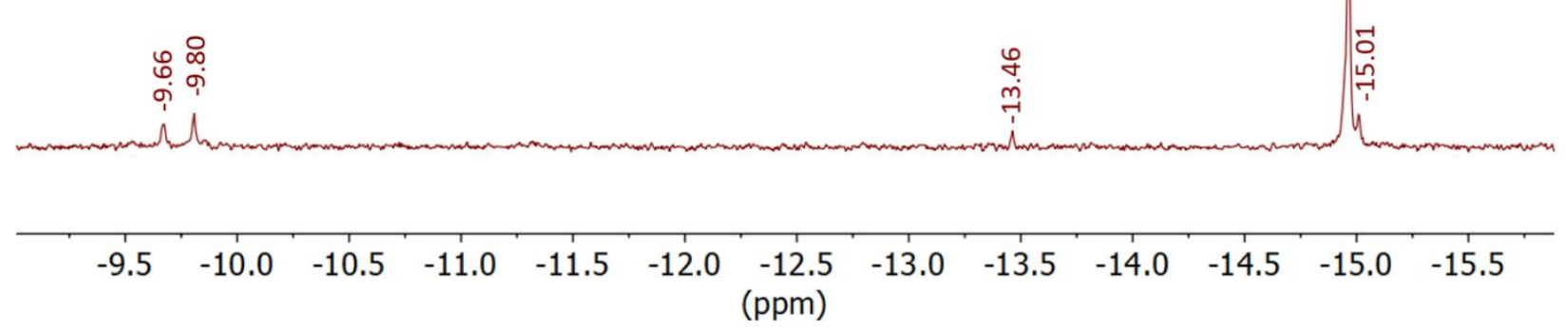

Figure S2. Stacked ${ }^{31} \mathrm{P}-\mathrm{NMR}$ spectra of the isolated title compound, $\mathrm{POM}_{\mathrm{Ge}}-\mathrm{COOH}$ (middle, green trace), its unsubstituted monolacunary precursor (top, blue trace), and a sample taken from the amide coupling solution after the attachment procedure (bottom, maroon trace), each dissolved in $\mathrm{CD}_{3} \mathrm{CN}$. Retention of the primary peak near $\delta-14.9$ ppm indicates the Ge-substituted POM core underwent negligible decomposition after $\sim 24 \mathrm{~h}$ exposure to the amide coupling conditions. 


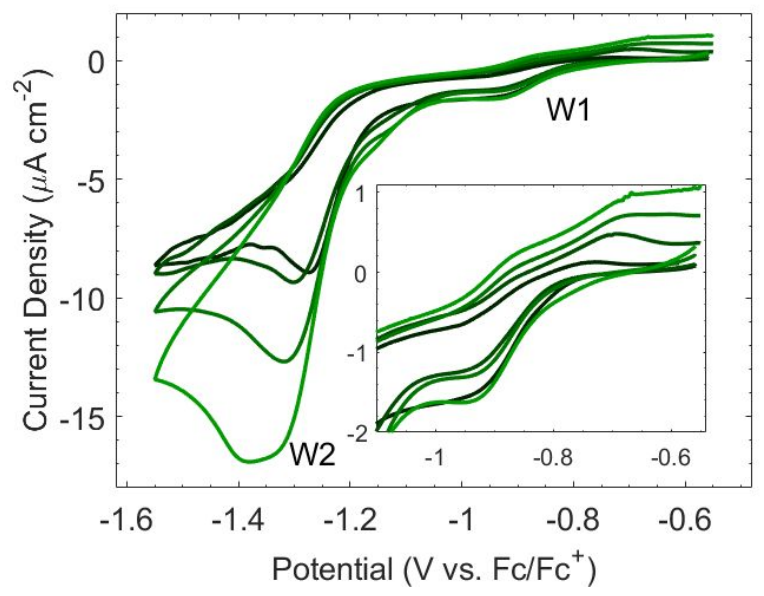

Figure S3. Representative CVs of a $\boldsymbol{n}^{+}-\mathbf{S i} \mid \mathbf{P O M}_{\mathbf{G e}}$ working electrode at different scan rates: $2,5,10, \& 20 \mathrm{mV} \mathrm{s} \mathrm{s}^{-1}$ demonstrating the growth of the anodic shoulder positive of the W1 anodic peak and the broadening of W2 with increases in scan rate. The inset shows a magnified view of W1. CV traces change color from black to green as scan rate increases. Measurements were taken with the working electrode in contact with dry MeCN containing $0.1 \mathrm{M} \mathrm{TBABF}_{4}$ electrolyte using a GC working electrode, a Pt mesh counter electrode, and a Ag wire quasi reference electrode. Ferrocene was added at the end of the experiment to provide an internal standard. 


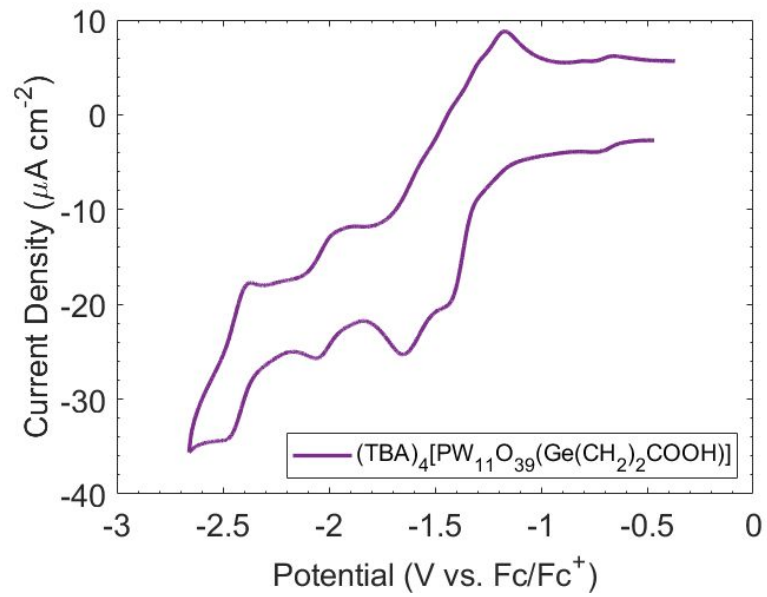

Figure S4. Cyclic voltammogram of $1 \mathrm{mM} \mathrm{POM}_{\mathrm{Ge}}-\mathrm{COOH}$ in dry $\mathrm{MeCN}$ with $0.1 \mathrm{M}^{\mathrm{TBAPF}} \mathrm{F}_{6}$ electrolyte using a GC working electrode, a Pt mesh counter electrode, and a Ag wire quasi reference electrode. The scan rate was $50 \mathrm{mV} \mathrm{s}^{-1}$. Ferrocene was added at the end of each experiment as an internal standard. 


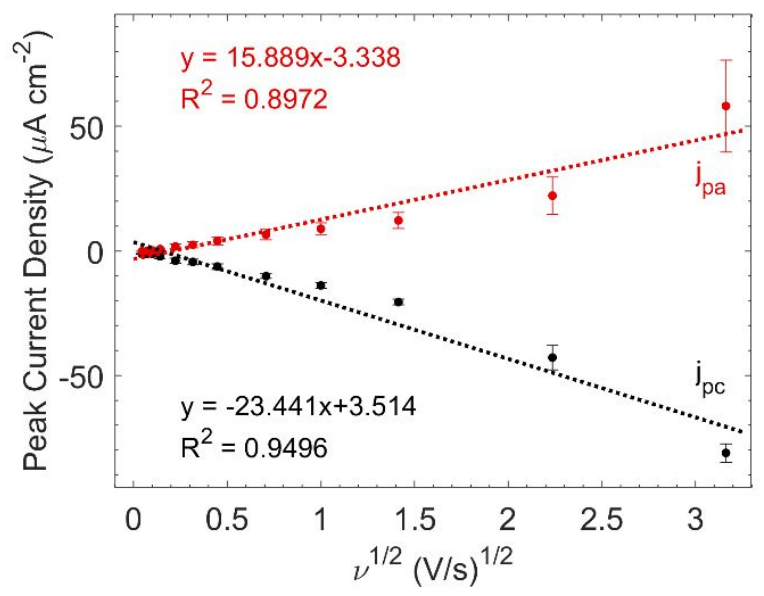

Figure S5. Average peak cathodic $\left(j_{p c}\right.$, black) and anodic $\left(j_{p a}\right.$, red) current densities for W1 vs. the square root of the scan rate $\left(v^{1 / 2}\right)$ with error bars indicating standard error. Dashed linear trend lines are included with their respective equations and $\mathrm{R}^{2}$ values. The weak trends of $j_{p c}$ and $j_{p a}$ with $v^{1 / 2}$ indicate $\mathrm{W} 1$ is unlikely a diffusion-controlled redox event. 


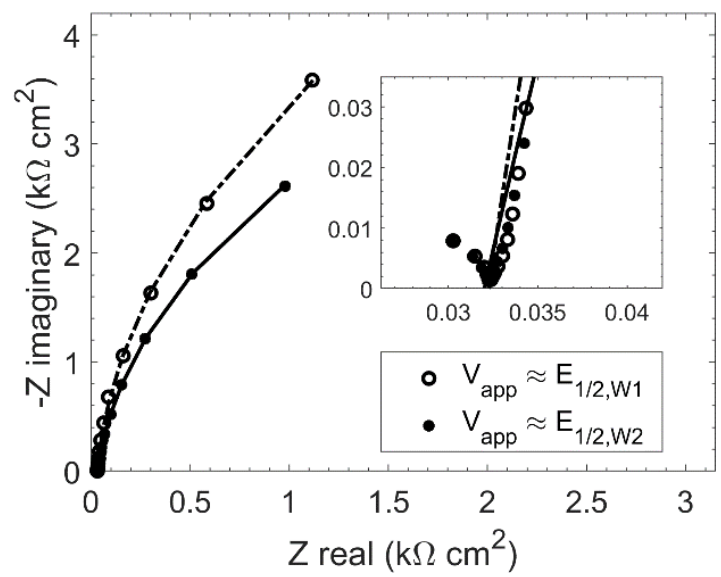

Figure S6. Representative Nyquist plots of $\boldsymbol{n}^{+}-\mathbf{S i} \mid \mathbf{P O M} \mathbf{M}_{\mathrm{Ge}}$ electrodes taken at $\mathrm{V}_{\text {app }}=-0.91 \mathrm{~V} \mathrm{vs.} \mathrm{Fc/Fc}{ }^{+} \approx \mathrm{E}_{1 / 2 \text {, w1 }}$ (open circles) and $\mathrm{V}_{\text {app }}=-1.31 \mathrm{~V}$ vs. $\mathrm{Fc} / \mathrm{Fc}^{+} \approx \mathrm{E}_{1 / 2 \text {,W2 }}$ (filled circles). Associated fits of this EIS data using the modified Randles circuit depicted in Chart 1 are indicated by the dashed and solid curves, respectively. 


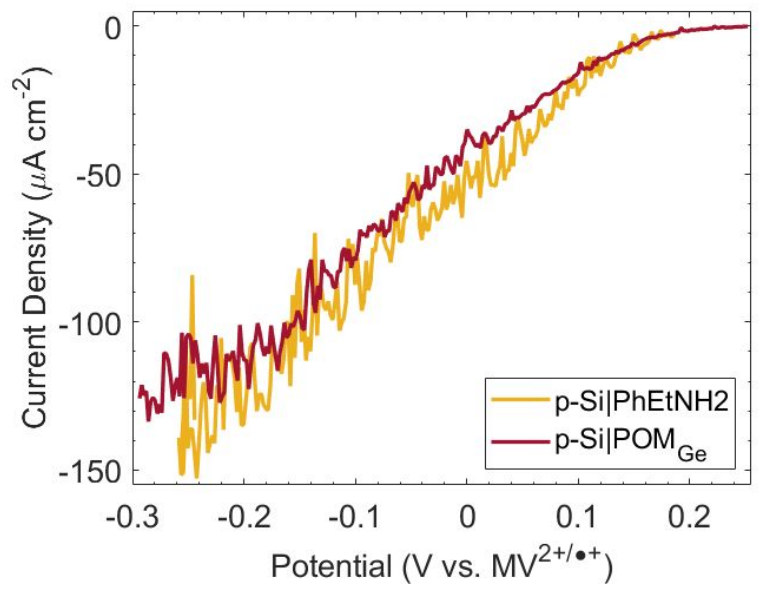

Figure S7. LSV curves for POM- and $\mathrm{PhEtNH}_{2}$-modified $p$-Si(111) photoelectrodes in contact with saturated $(\sim 1.5 \mathrm{mM}) \mathrm{MV}^{2+}$ and $0.1 \mathrm{M} \mathrm{TBABF}_{4}$ in dry MeCN under illumination. Stirring was held at $700 \mathrm{RPM}$ and the potential was swept at $25 \mathrm{mV} \mathrm{s}^{-1}$. 


\section{References}

(1) Plymale, N. T.; Kim, Y.-G.; Soriaga, M. P.; Brunschwig, B. S.; Lewis, N. S. Synthesis, Characterization, and Reactivity of Ethynyl- and Propynyl-Terminated Si(111) Surfaces. J. Phys. Chem. C 2015, 119 (34), 19847-19862. https://doi.org/10.1021/acs.jpcc.5b05028. 